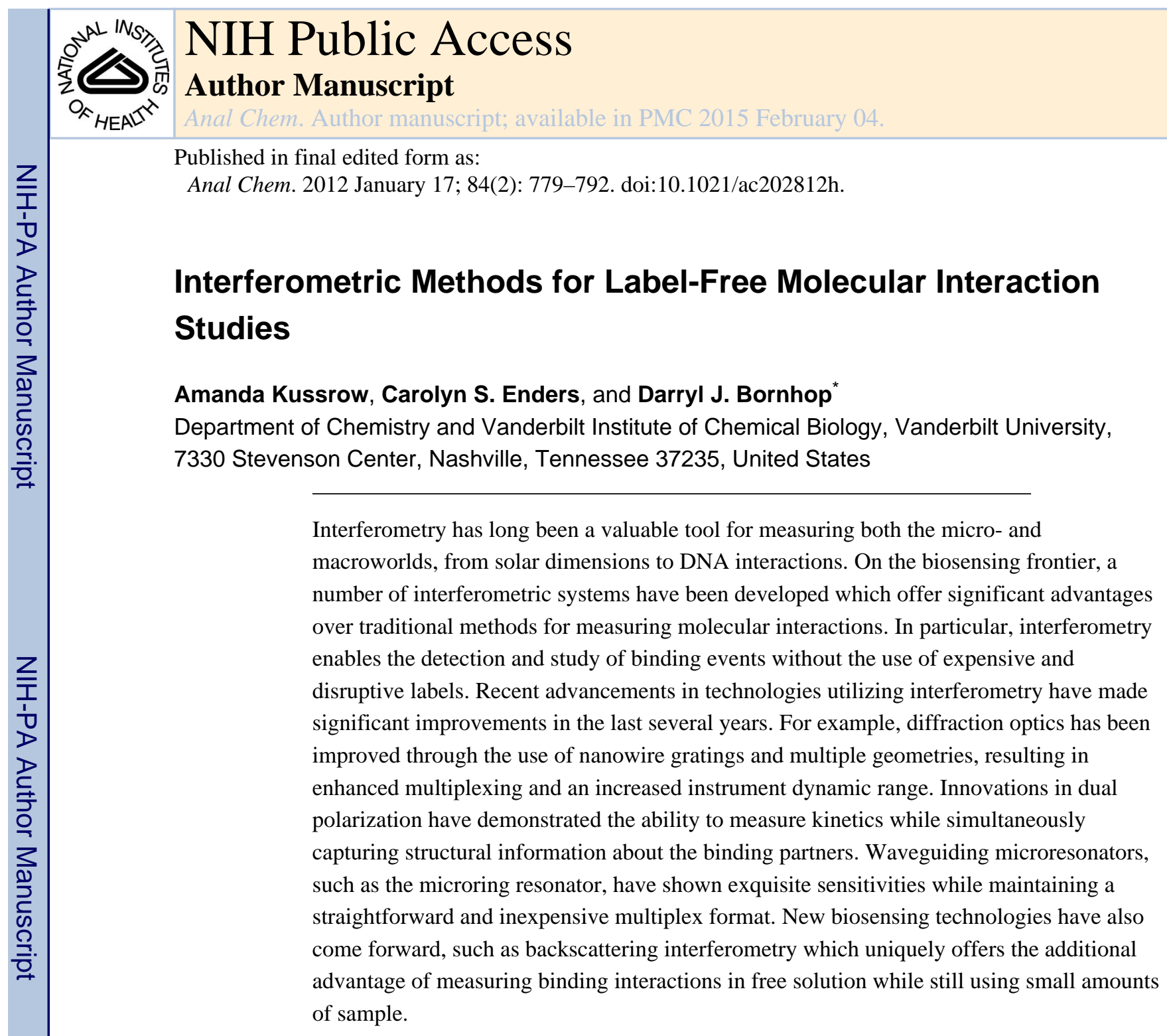

\title{
APPLICATIONS OF INTERFEROMETRY
}

When two or more light waves are superimposed, an interference pattern is created. When these patterns are studied, the properties of the light waves and of the material that they have been in contact with can be explored. This field, known as interferometry, has led to the development of some of the most sensitive optical techniques available and has been applied to various applications, including astronomy, metrology, oceanography, seismology, and biological sciences.

Interferometry was first applied in the field of astronomy over two centuries ago to investigate why stars appear larger through a telescope relative to other objects. ${ }^{1}$ Later, the technique was utilized to determine the actual diameter of various astronomical objects. ${ }^{2,3}$ Today, astronomical interferometers have provided some of the highest resolution images of our galaxy. ${ }^{2}$ In the field of applied metrology, interferometry is an essential tool used to

(C) XXXX American Chemical Society

"Corresponding Author: Phone: 1.615.322.4404. Fax: 1.615.322.2861. darryl.bornhop@ vanderbilt.edu.

Special Issue: Fundamental and Applied Reviews in Analytical Chemistry 
characterize optical components; for example, the technique may be used to detect deformations in mirror blanks or to inspect the quality of a lens or an optical fiber. ${ }^{4-6}$ In oceanography, interferometry has been used for imaging ocean surface features, such as currents and wave movements. ${ }^{7,8}$ Seismology frequently utilizes interferometry to image the topography of the earth and can be used to measure and study deformations caused by events such as earthquakes and explosions. ${ }^{9,10}$

Interferometry has also been used in the biological sciences as a tool to monitor and quantify molecular interactions. Within this field, interferometry offers the dual advantage of being a highly sensitive technique that does not require the use of expensive molecular labels. Therefore, molecular interactions may be characterized with both binding partners in their native states, eliciting quantitative, meaningful (i.e., unperturbed by labeling) affinity data in a cost-effective format. An excellent 2006 review by Ince et al. compares relevant parameters for a number of sensors within the three main categories of contemporary biosensing techniques (surface plasmon resonance (SPR), luminescence (requiring labeling), and interferometry) and makes generalizations concerning the relative performance of these methods. ${ }^{11}$ In summary, this review suggests that interferometric measurements gave superior results to SPR when a probe other than an antibody was used and exclusively allowed for the best resolution for low molecular weight compounds. While luminescence techniques were generally found to offer the best detection limits for the applications reviewed, it is well-established that labeling of compounds can present a number of complications. In addition to adding complexity and cost, ${ }^{12-17}$ labels can interfere with an assay by perturbing the native interaction of the biospecies through steric hindrance or occlusion of the binding site, resulting in changes in the binding pair affinity or false negatives. ${ }^{12,17-20}$ The fluorescence signal generated by labeling may also be sensitive to perturbations by local field intensity, $\mathrm{pH}$, and temperature, may be subject to bleaching and quenching, and may suffer from false positives due to background binding and/or autofluorescence of compounds. ${ }^{12,21}$ Heterogeneity of fluorescent labeling is also a significant challenge, ${ }^{20,22}$ presenting particular difficulty in quantifying binding energy and expression levels with confidence and reproducibility in microarray formats. ${ }^{23}$ Furthermore, prior knowledge of the target molecule is necessary to incorporate labeling. ${ }^{24}$ Recently, we used BSI to begin to quantify some of the perturbations caused by adding a fluorophore to a DNA binding pair. ${ }^{25}$

Both SPR and interferometry are label-free techniques which avoid complications that result from labeling. While it is a highly significant and widely used biosensing platform, SPR itself is not an interferometric technique and will not be discussed in detail in this Review. However, it is important to note that, in addition to the inability to match interferometry in the resolution of low molecular weight compound interactions, conventional SPR technology is characteristically less flexible in construction for miniaturization and multiplexing purposes. ${ }^{11,16}$ Here, we explore several different types of interferometers which have been successfully utilized to study molecular interactions, highlighting a few examples of each platform and then providing a more detailed summary of the newly introduced, free-solution technique, backscattering interferometry (BSI). 


\section{MACH-ZEHNDER INTERFEROMETER}

Techniques employing refractive interferometry for biosensing applications measure effective refractive index (RI) changes within an evanescent field, often induced by specific binding. Because RI is highly temperature dependent, refractometric methods must include temperature compensation via internal referencing, thermostats, or both. ${ }^{20,26} \mathrm{~A}$ classic evanescent-field refractive interferometer is the Mach-Zehnder interferometer (MZI), which utilizes a waveguiding method to monitor the difference in RI between a sample and reference arm of the waveguide. As shown in Figure 1A, a laser illuminates a singlemode waveguide which is then split into a sample and reference arm. The reference arm is coated with a thin cladding layer, while the sample arm has a window to allow the evanescent field to interact with the sample. The sensor and reference arms are then recombined, leading to beam interference. Any change in the sample's refractive index produces a phase shift in the sensor arm beam, which in turn results in a change in the output intensity when the two beams are recombined. Binding events are thereby measurable using photodetection. Intrinsically, the evanescent sensing approach of the MZI instrumental configuration requires a single polarization and single-mode illumination to prevent interference from cross-polarization and multimodal effects. The sensitivity of the MZI is typically correlated with the length of the sensing window, making it difficult to measure low concentrations of analytes without using large amounts of sample or long windows. ${ }^{27}$ However, the MZI configuration remains an attractive platform for many applications because of its inherent ability to nearly eliminate temperature-induced drift. ${ }^{28}$

The MZI configuration, shown in Figure 1A, was first used for biosensing in 1993 and has since been utilized in a broad range of applications. ${ }^{18,28-32}$ In 1997, Brosinger et al. demonstrated the ability to resolve a $2 \times 10^{-5}$ refractive index units (RIU) with their early MZI configuration. ${ }^{29}$ Initial experiments to test the biosensing ability of the instrument were also reported, demonstrating that MZI can detect fetal calf serum binding nonspecifically to the sensor surface. ${ }^{29}$ More recently, Prieto et al. used a Mach-Zehnder interferometer total internal reflection (MZI-TIR) configuration to achieve a minimum refractive index change of $7 \times 10^{-6}$ at the sensor surface. The utility of the instrument was demonstrated by detecting the interaction between a covalently immobilized pesticide and its antibody in PBST (phosphate buffered saline Tween). ${ }^{30}$ The same group also constructed an MZI based on an antiresonant reflecting optical waveguide (ARROW). The use of ARROW structures instead of conventional TIR waveguides allows for larger core and rib dimensions, making the instrument more compatible with mass-production and also lowering insertion losses. However, these advantages are accompanied by a loss in sensitivity: the minimum detectable refractive index change for the MZI-ARROW was found to be $2 \times 10^{-5.31}$

In 2009, Densmore et al. reported a silicon-on-insulator (SOI) photonic wire waveguide sensor which utilized multiple spiral waveguides in the balanced MZI configuration to achieve high sensitivity in a multiplexed array format. The sensor was used to measure specific IgG/anti-IgG interactions with a resolvable surface coverage of $\sim 0.25 \mathrm{pg} / \mathrm{mm}^{2}(0.5$ fg per spiral waveguide), a sensitivity that corresponds favorably with commercial SPR sensors with the added advantage of multiplexing abilities. This achievement is largely owed to the use of thin SOI waveguides which allow a higher response to surface interactions than 
other materials since the compact size and high RI contrast produce an unusually strong evanescent field at the sensor surface. ${ }^{28}$ SOI photonic waveguides have also been employed in other evanescent- field sensor configurations, such as microring resonators (described later), and are attractive because of the aforementioned advantages as well as their low cost. $^{33}$

\section{YOUNG INTERFEROMETER}

Another waveguiding interferometer is the Young interferometer (YI). The YI configuration (Figure 1B) includes a single-mode laser illuminating a single-mode waveguide, which is then split into a sample and reference arm, as in the Mach-Zehnder interferometer.

However, instead of the interference being created when the waveguides recombine as in the MZI, in a YI, the optical output of the waveguides interact in free space to create the interference fringes, which are displayed onto a CCD camera.

The YI was first used to measure molecular interactions in $1994^{18}$ and has been widely published on thereafter. ${ }^{34-36}$ In 2003, Ymeti et al. showed that their multichannel YI configuration can measure four different analyte concentrations simultaneously, achieving a refractive index resolution of $8.5 \times 10^{-8}$ RIU. ${ }^{36}$ In 2006, Hradetzky et al. reported a refractive index detection limit of $0.9 \times 10^{-6}$ for their single-cell YI and detected the hybridization of 21-mer DNA with immobilized receptor DNA at the biosensor surface. ${ }^{34}$ Their findings suggested the detection limit of this DNA-DNA binding interaction to be in the picomolar range.

\section{HARTMAN INTERFEROMETER}

The Hartman interferometer (HI) is also a waveguiding technique; however, in contrast with the MZI and YI, this approach utilizes a planar waveguide that is patterned with lines of immobilized molecules. Light is directed into the waveguide through a grating to create a single broad beam (Figure 1C). The light then passes through parallel sensing regions which are coated with different receptors to create distinct binding and control regions. Next, the light travels though integrated optics that combine the light from neighboring regions to create interference. The interference signals then pass through another grating and to the detector. The phase shift of the interference patterns is measured to detect refractive index changes.

In 1997, Schneider et al. demonstrated the broad applications of the HI as a real-time detector of nucleic acid, protein, and pathogen analytes. Experiments were performed by immobilizing the receptor (anti-hCG antibody) to the sensor surface, allowing for real-time detection of human chorionic gonadotropin (hCG) with a direct detection limit of $2 \mathrm{ng} / \mathrm{mL}$ in phosphate buffered saline (PBS). DNA hybridization experiments detected a four-base mismatch in $50 \%$ formamide hybridization buffer, and a nucleic acid detection capability of $10^{11}$ copies per $\mathrm{mL}$ was achieved. ${ }^{37}$ In early 2000 , the same group expanded on these applications, demonstrating the ability of their configuration to detect hCG in human serum at clinically relevant levels of $0.1 \mathrm{ng} / \mathrm{mL}$. Extensive studies of the nonspecific binding associated with serum samples were also performed, which concluded that the HI can overcome this particular setback using a reference region and controlled surface 
chemistry. ${ }^{38}$ Later that year, Schneider et al. took their studies a step further by detecting hCG in whole blood, which is an impressive result for a label-free sensor. Despite significantly higher background levels than buffer or serum systems, a clinically relevant detection limit of $0.5 \mathrm{ng} / \mathrm{mL}$ hCG was achieved. ${ }^{39}$

\section{DIFFRACTION OPTICS}

Diffraction-based sensing employs a similar technique of immobilizing the probe molecules into a pattern that will diffract the incoming laser light to create an interference pattern. This pattern has been shown to change as sample is introduced and binding occurs on the stripes of capture species, resulting in a change in the height and refractive index of the diffraction grating. The intensity of the refractive spots is measured using a photodetector, allowing any changes within the sample to be measured. In theory, a significant advantage of diffractionbased sensors is that a diffraction signal is only created when biomolecules bind specifically to the patterned substrate; therefore, nonspecific binding to the sensor surface is not detected. ${ }^{40}$ While many applications of diffraction optics offer enhanced performance when used in conjunction with labeling strategies, such as the recent work done by Penner and Corn using DNA-coated gold nanoparticles ${ }^{41}$ the following examples focus primarily on label-free applications of the technique. Early studies by St. John et al. demonstrated that diffraction optics can be used to detect whole bacteria cells captured using an antibody grating stamped on a silicon surface. ${ }^{42}$ In 2005 , Goh et al. demonstrated the ability of diffraction optics to measure two different binding interactions simultaneously without the use of labels. To achieve this, receptor molecules mouse IgG and rabbit IgG were immobilized in two different patterns via PDMS stamping on the same 2D surface. Antimouse IgG and antirabbit IgG were then introduced into the cell sequentially. The binding observed for each pattern indicated the specific binding of the target analyte exclusively to its receptor antibody. These findings, along with other antibody studies, carry implications for diagnostic applications involving multiple markers and/or competition assays (Figure 2A,B). ${ }^{13,43,44}$ Currently, Axela Biosensors offers a commercialized diffraction-based sensor known as the dotLab System which enables multiplexing of immunoassays over a broad dynamic range. In 2007, they demonstrated the ability to simultaneously measure binding of two similar sets of antibody/analyte pairs with concentrations which differed by 6 orders of magnitude; however, labeling strategies were implemented to measure the analyte of lower concentration. ${ }^{45}$ Recently, work has been performed using nanowire gratings in order to increase sensitivity through the use of external and total internal reflection geometries (Figure 2C). ${ }^{40}$

\section{DUAL POLARIZATION}

The dual polarization interferometer (DPI) is another waveguide method for studying molecular interactions. This technique utilizes two waveguides, a sample and reference waveguide, which are stacked together, so they may be illuminated by a single laser (Figure $3 \mathrm{~A})$. The light exiting the waveguides form an interference pattern in the farfield. In contrast with other waveguide sensors, the polarization of the laser in the DPI is alternated so that two polarization modes of the waveguides are excited in succession in order to modulate the signal and increase sensitivity. Using the information from the measurements of both 
polarization states and the refractive index, the thickness of the adsorbed protein layer can be calculated.

In 2003, Swann et al. measured the binding and surface loading of streptavidin to the biotinfunctionlized surface of their DPI. Nonspecific binding, thickness, and density changes of protein layers as well as other structural aspects of the streptavidin -biotin system were also explored in detail using this tool. ${ }^{46}$ In 2006, Lin et al. used DPI to derive dissociation constants $\left(K_{\mathrm{D}}\right)$ for homopolyvalent pentameric C-reactive protein (CRP) with monoclonal anti-CRP IgG; these values were in close agreement with those previously derived using enzyme-linked immunosorbent assays (ELISA). ${ }^{47}$ That same year, Ricard-Blum et al. measured the interaction of immobilized heparin with heparin binding protein HepV. Exploring the stochiometric and kinetic parameters of this binding system using DPI lent insight into collagen $\mathrm{V}$ interaction with proteoglycans in tissues, a process which affects collagen fibril formation. ${ }^{48}$ In 2009, Wang et al. utilized DPI to measure the structural changes of electrostatically immobilized DNA upon binding to small molecules ethidium bromide and spermine in real time. ${ }^{49}$ These experiments were then extended to monitor the association and dissociation of mitoxantrone and methylene blue with DNA (Figure 3B). ${ }^{50}$ Changes in mass, thickness, and refractive index of the DNA sample layer were monitored upon small molecule binding. These studies demonstrated the power of DPI in that it can be used to measure structure and kinetics simultaneously and potentially has the flexibility to interrogate binding interactions over a large molecular size range. ${ }^{49,50}$ Farfield Sensors, Ltd. has been commercializing DPI-based biosensing systems since 2000 with the introduction of the AnaLight $250^{26,51}$ and has most recently released the AnaLight $4 \mathrm{D}$ which is touted to enable the measurement of structural changes within lipid bilayers. ${ }^{52,53}$

\section{WAVEGUIDE MICRORESONATORS}

From our perspective, the microresonator approach represents one the most promising for measuring multiple molecular interactions, label-free and at physiologically relevant sensitivity levels. Recently, the concept of microresonance has been applied to waveguide methodologies to provide compact, high-sensitivity biosensors with large Q (resonance) factors (Figure 4A). ${ }^{19,24,27,54,55}$ While sensitivity is limited when a given photon only interacts once with an adsorbate as in traditional waveguide methods, multipass resonance methods allow light to encounter the analyte many times to enhance sensitivity. Specifically, microresonators use a circular configuration and harness total internal reflection to increase photon lifetime as light circumnavigates the waveguide "micro-race track," achieving resonance at a particular resonance wavelength. Changes in optical path length (RI) induced by binding to the waveguide surface disrupt the resonance wavelength, allowing interactions to be monitored using a tunable laser. A higher number of recirculations within the sensor translates into a longer photon energy decay time and a narrower resonance line width. The narrower the resonance line width achieved, the higher the $\mathrm{Q}$ factor of the device and the greater the sensitivity. ${ }^{17,19,24,27}$

In 2007, Armani et al. introduced their whispering-gallery mode (WGM) microtorid biosensor which has notably reported detection of single-molecule binding as part of a 12 decade dynamic range. Detection of IL-2 interactions in both pure solution and in serum 
were demonstrated, and single-molecule binding was measured for a variety of molecular cross sections. To explain this remarkable sensitivity, this work describes a thermo-optic mechanism resulting from circulation-induced local heating of bound molecules which, giving an additional redshift when molecules interact at the surface, enhances the resonance shift already induced by changes in optical path length from sensor surface binding. The ultra high $\mathrm{Q}$ factor of this resonator $\left(\mathrm{Q}>10^{8}\right)$ allows heightened sensitivity in both the thermo-optic effects and the direct RI changes due to surface binding. Also of note is the finding that molecules at the equatorial plane of the biosensor are polarized to give the maximum wavelength shift on the sensor surface. ${ }^{24}$

A 2008 Nature Methods: Perspectives article by Vollmer and Arnold highlights that various geometries and materials are possible for use in WGM setups, even those compatible with planar substrates, as long as light recirculation allows resonance to be excited. The group cites their work with a microsphere WGM sensor which was used to detect protein and DNA interactions with unprecedented sensitivity of $1 \mathrm{pg} / \mathrm{mm}^{2.19}$

While exquisite sensitivity is possible with resonator approaches, many of the configurations are not particularly practical with respect to implementation, requiring tedious alignment and quite a bit of optical sophistication. To circumvent this limitation, Bailey and coworkers ${ }^{20,56-58}$ have capitalized on the maturity of standard lithographic methods and offthe-shelf optical communications technology demonstrating the microring resonators integrated onto a standard silicon substrate or silicon-on-insulators (SOI). In their early work, they show that interactions can be studied with good sensitivity, measuring binding kinetics and quantifying analyte concentrations, using a somewhat clever approach that estimates the slope for the association curve. ${ }^{20}$

In our opinion, the microring resonator technology is most exciting when one considers that it is relatively straightforward and inexpensive to multiplex. The use of SOI on-chip microring resonators in an array format ${ }^{20,57,58}$ has been shown to detect protein cancer biomarker, such as CEA and PSA, in pure serum at clinically relevant levels (5-100 ng/ $\mathrm{mL}$ ) ${ }^{58}$ The $2 \mathrm{ng} / \mathrm{mL}$ limit of detection found for this system (reduced to $25 \mathrm{ng} / \mathrm{mL}$ in serum) compares well with a parallel ELISA kit assay but offers increased accuracy. This report illustrates that SOI microresonators could be particularly well-suited for multiplexed biosensing because both the waveguide and the ring can be integrated in a single, easy-tofabricate chip format. Here, the biosensing array format is achieved by directing the beam into different input grating couplers and linear waveguides etched onto a Si substrate. Each of these waveguides leads to a unique microring, allowing serial evaluation of the resonance wavelength from each. In this way, each microring must be independently calibrated. ${ }^{20} \mathrm{An}$ expansion of this concept demonstrated the ability to use 64 microrings and enabled the detection of 16 attomoles of sequence-specific DNA hybridization. The group continues to expand their work to multiplex sensor chips by putting 4 different proteins on a single sensor, although initial crosstalk has been observed in their preliminary experiments. ${ }^{22}$ Recent work has applied this technology to the study of microRNAs, allowing for the distinction of single nucleotide polymorphisms and quantitation down to an amount of 150 fmol. ${ }^{57}$ This technology is being commercialized by Genalyte Inc., San Diego, CA, (http:// 
www.genalyte.com/), which is a late-stage start-up company that, at the time of this Review, is soliciting collaborations for the third generation technology. ${ }^{56,59,60}$

\section{SURFACE PLASMON RESONANCE INTERFEROMETRY}

A surface plasmon is an evanescent wave resulting when an electromagnetic beam is directed along a metal-dielectric (metal-liquid or metal-glass, e.g.) interface and excites electrons at the metal surface to oscillate. When coupled with a photon, these excitations are known as surface plasmon polaritions (SPP). The most well-known application of SPP modes is surface plasmon resonance (SPR), a commercialized biosensing technique that measures biomolecular interactions via changes in RI at the sensor surface. SPR refers to the resonance of electrons which occurs when incident light is coupled to the surface plasmon, causing a resonance reflectance dip at which changes in light intensity can be monitored. The resonance frequency of the SPP mode is dependent on the RI at the interface of the metal film and the dielectric medium. Therefore, changes in RI at the sensing surface cause changes in the optical properties of the SPP. As aforementioned, conventional SPR technology is inferior to interferometry in resolving low molecular weight compound interactions and is less amenable to compact design and multiplexing purposes. ${ }^{11,16,61}$ To challenge these limitations, several groups have combined aspects of SPR technology with interferometry to achieve hybrid RI sensors which retain more sensitivity than conventional SPR's when miniaturized. ${ }^{61,62}$

An early SPR-interferometry device developed by Nikitin et al. in 2000 used inteferometry to monitor the phase of the beam reflected by SPR instead of the intensity as in conventional SPR methods. Because it was found that phase can change more abruptly than intensity, higher sensitivity was enabled while maintaining a wide dynamic range. ${ }^{63,64}$ It has since been further established that the detection of phase changes allowed by interferometry enables a consistent improvement in sensitivity over traditional SPR monitoring methods. ${ }^{11,65}$ Similarly, Wu et al. developed an SPR-interferometric sensor utilizing SPR and heterodyne interferometry which also incorporated a total internal reflection device (TIR) to achieve an estimated order-of-magnitude sensitivity improvement over conventional SPR techniques of the time. ${ }^{64}$

In 2007, Kim et al. developed a user-friendly, microarray- and microfluidics-compatible hybrid platform combining localized SPR (LSPR) and interferometry. The technology utilizes a gold-deposited porous anodic alumina (PAA) layer chip or a "gold-capped nanostructure" to monitor changes in both wavelength shifts and relative reflected intensity (RRI) at the chip surface. The measurement of specific DNA hybridization at a detection level of $10 \mathrm{pM}$ and a linear range of $10 \mathrm{pM}$ to $10 \mu \mathrm{M}$ target DNA was achieved, and the biosensor is currently under further development to target multiplexed point-of-care applications. ${ }^{62}$ A more recently developed hybrid biosensor is the vertical plasmonic MachZehnder interferometer (VPMZI) by Gan et al. in 2009. In the VPMZI setup, SPP modes on top and bottom surfaces of a metal film (deposited on a glass substrate) interfere with each other, mediating a far-field interference pattern, and could potentially enhance the sensitivity of RI-based biosensing. This is essentially a plasmonic MZI, with the sensing arm being the top surface and the reference arm at the bottom surface of the metal film. While still under 
development, the current apparatus has demonstrated both a high degree of simplicity and the potential for high sensitivity in comparison with other nanoplasmonic devices and is compatible with optics-on-a-chip miniaturization. ${ }^{61}$ In 2010, Kong et al. combined SPR with differential spectral phase interferometry, using a white light source, as opposed to a laser source, in order to expand the measurement range up to $10^{-2}$ RIU while still maintaining sensitivity (detection limits of $3.3 \mathrm{pM}$ ) with a label-free format. ${ }^{66,67}$

\section{POROUS SI, AL, AND TI SENSORS}

Porous substrate sensors have been developed using the principles of the Fabry-Perot interferometer within porous structures etched in silicon, aluminum, or titanium-based thin films. Reflective interferometers, including Fabry-Perot interferometers, rely on the interference of portions of light reflected off different surfaces within the sensor. In biosensing applications, the two surfaces may be the top and bottom interfaces of the sensing layer, including functionalized portions and their bound substrates (Figure 5). In contrast to refractive interferometers, biosensors based on reflective interferometry measure optical density, which is a product of RI and physical layer thickness. Changes in these properties of the layer due to binding are measured for biosensing applications. Because changing the temperature affects RI and physical thickness inversely (an increase in temperature causes a decrease in RI but an increase in thickness due to thermal expansion), temperature does not need to be controlled with the precision required for refractive techniques. ${ }^{26,68}$

Generally, in these methods, the porous film acts as the interferometer, creating fringes from reflections off the top and bottom of the pores. As demonstrated by Sailor et al. in 1999, this technique can overcome typical penetration depth limitations because the entire volume of the sample within the film is utilized for the measurement. ${ }^{69,70}$ Limited penetration depth, or the inability to measure interactions which occur above the sensor surface, is a significant shortcoming present in other surface-based techniques. In addition to this advantage, the ease of fabrication, large internal surface area, and the ability to easily modify the surface make porous substrate sensors a good choice as biosensing tools. ${ }^{71,72}$ Porosity, thickness, and pore size can be adjusted and optimized according to the assay requirements, ${ }^{73}$ an important feature since pore size determines both the size of molecules which can readily diffuse into the pores as well as the sensitivity (larger pores sizes decrease sensitivity). ${ }^{74}$

A 1997 Science paper by Lin et al. reported the ability of a porous silicon-based optical interferometric bionsensor to detect the binding of small molecules, DNA oligomers, and proteins with unprecedented sensitivity (pico- and femtomolar concentrations). ${ }^{70}$ In 1999, Dancil et al. studied protein A and IgG binding via porous silicon biosensing. This report highlighted the reversibility and stability of the system, as well as the ability to render the sensor insensitive to nonspecific binding. ${ }^{69}$ A 2003 publication in Science by Li et al. demonstrated that porous silicon can serve as a template for the construction of complex optical structures (composed of organic polymers or biopolymers, e.g.) in biosensor applications. These findings are of particular interest to drug delivery applications. ${ }^{75}$ 
In the past decade, the variety of biosensors employing porous substrates has expanded immensely. In addition to utilizing other porous materials such as porous alumina and porous titanium oxide, the microresonating properties of photonic crystal micro-cavities made from these porous substrates have been well developed for high-sensitivity biosensing. A 2009 report by Alvarez et al. highlighted the improvement in stability of porous anodic aluminum oxide $\left(\mathrm{pAl}_{2} \mathrm{O}_{3}\right)$ over porous $\mathrm{Si}$ at physiological $\mathrm{pH}$ and demonstrated the utility of the sensor for real-time kinetic determinations of protein binding. ${ }^{73}$ The same group also utilized thin films of titanium oxide $\left(\mathrm{TiO}_{2}\right)$ nanotube arrays, which allowed stability over an even larger $\mathrm{pH}$ range $(\mathrm{pH} 2-8)$ and provided greater RI contrast with the aqueous medium to increase the signal-to-noise ratio, enhancing sensitivity. ${ }^{71}$ Photonic crystal microcavity biosensors made in SOI substrates reported by Lee and Fauchet in 2007 provided $2.5 \mathrm{fg}$ of BSA monolayer detection limits and enabled detection of BSA to glutaraldehyde (nonspecific) and biotin-streptavidin (specific) binding. ${ }^{14}$ Later that year, the same group expanded on these studies to enable quantitative femtomolar detection of intmin binding and demonstrated for the first time that microporous $\mathrm{Si}$ can be used to selectively and quantitatively detect specific target protein with a micromolar dissociation constant $\left(K_{\mathrm{D}}\right)$ in crude bacterial lysate. ${ }^{74}$ At the time of these studies, the sensitivity of this particular sensor fell short of enzyme-linked immunosorbent assays (ELISA) or 2D polyacrylamide gel electrophoresis (2DPAGE) but had advantages in ease of fabrication and use. It appears that these approaches, as with many techniques, exhibit significant performance degradation when working with complex matrixes, such as serum or cell free-media.

Silicon Kinetics Inc. (http://www.siliconkinetics.com/) has been commercializing a form of porous Si interferometry since 2002 and provides products to perform biomolecular measurements in either a flow-cell or 96-well plate configuration. ${ }^{76-78}$ One strength of this approach is the capability to measure very slow off-rates ${ }^{79}$ as needed to fully evaluate therapeutic antibodies.

\section{BIOCD}

The biological compact disk (BioCD) utilizes patterns of immobilized capture proteins on a disk with a mirrored surface to create periodic reflective interference spectra which are measurably altered by binding. ${ }^{80,81}$ The interference signal is interrogated before and after the disk has been incubated with the sample, and the difference is correlated to the amount of binding that has occurred. The large surface area of the disk allows the BioCD to be used for multiplexing purposes when a $2 \mathrm{D}$ scanning system is employed. ${ }^{21}$ Unfortunately, because the BioCD discretely measures the relative difference in the reflectance patterns of surface immobilized proteins before and after binding, the tool is not readily applicable for real-time monitoring, rendering kinetics studies problematic.

Detection limits as low as $10^{5}$ molecules have been achieved using the BioCD, which was employed to measure specific binding between antimouse $\mathrm{IgG}$ and mouse IgG using rabbit IgG as a control. ${ }^{80,81}$ In an expanded effort, it was shown that binding measurements are concentration dependent, illustrating the potential of the technique for quantitative analyses. ${ }^{82}$ In 2009, Wang et al. expanded applications of the technique further by employing the BioCD to perform multiplexed prostate specific antigen (PSA) detection in 
human serum. ${ }^{83}$ In 2011, the group achieved a $4 \mathrm{ng} / \mathrm{mL}$ PSA detection limit in undiluted serum $(1 \mathrm{ng} / \mathrm{mL}$ in 1:4 serum) against a protein background of $10 \mathrm{mg} / \mathrm{mL}$, by employing subtraction, surface-modification, and blocking techniques to suppress nonspecific binding. ${ }^{21}$

\section{OTHER REFLECTIVE INTERFEROMETRY PLATFORMS}

A reflective interferometry technique known as biolayer interferometry has recently been commercialized by ForteBio in a microfluidic-free instrument known as the Octet. This technology allows analyte in multiple samples to be quantified rapidly ( 200 samples/h) in a standard 96-well plate by coating disposable fiber-optic-based sensors with capture molecules and inserting them into the sample wells. Light is directed down the fiber-optic sensor, and reflected light travels back along the fiber to a spectrometer. Upon analyte binding to the sensor surfaces, the reflected interference pattern is measurably changed. Notably, undiluted crude samples can be analyzed since signal is only generated at the sensor surface. ${ }^{84,85}$ Additionally, the Octet can be used to determine kinetics for binding interactions as demonstrated by Abdiche et al. in 2008. This report shows comparable binding affinities determined by the Octet with those determined using commercial SPR platforms under the same assay conditions. However, the sensitivity of the Octet in measuring direct binding of small molecules fell short of these SPR platforms, limiting the assay orientations possible with the system. Nevertheless, the ability to perform highthroughput, microfluidic-free assays with a cost comparable to an ELISA assay is an attractive advantage for many biosensing applications. ${ }^{86}$

Another promising reflective biosensor, first introduced as reflective interferometry (RI) ${ }^{15}$ and later renamed arrayed imaging reflectometry (AIR), ${ }^{16}$ is based on the disruption of destructive interference conditions upon substrate binding to a coated, functionalized silicon substrate. ${ }^{15,16,87} \mathrm{Lu}$ et al. reported the use of RI/AIR to detect oligonucleotide hybridization (femtomolar quantities of DNA), ${ }^{15}$ and the same group demonstrated sensing of proteinprotein interactions using this technique (detecting target intimin at $10 \mathrm{pM}$ ). ${ }^{16,87}$ However, careful control of the oxide thickness or wavelength and excellent source collimation were necessary to meet RI/AIR complete destructive interference conditions. These requirements were later eliminated by instead ensuring that the incident light straddles the Brewster angle to create the destructive interference, allowing the system to be insensitive to probe light bandwidth, collimation, and oxide thickness in homogeneity. The group called this improved, more practical version of their technique Brewster-angle straddle interferometry (BASI), which was used to detect thrombin binding to immobilized DNA aptamers at $26 \mathrm{nM}$ thrombin, a comparable sensitivity to SPR and ELISA methods. ${ }^{88,89}$

Recently, the principles of reflectance interferometry used in porous silicon, BioCD, and BASI methods have been applied to other biosensor variations with increased multiplexing abilities. In particular, Ozkumer et al. have introduced a multiplex platform known as the spectral reflectance imaging biosensor (SRIB) designed for high throughput use. SRIB is based on the optical phase difference rendered by the binding of biological species to probes on a transparent layered surface. This technique enables the collection of reflectance spectra for hundreds of spots on the array simultaneously. ${ }^{90,91}$ In 2010, this group demonstrated the 
ability to discriminate single base pair mismatch oligonucleotides in a 360-spot microarray format, which may be expanded to $10^{4}$ spots for high-throughput analysis of DNA-DNA interactions. ${ }^{23}$ Gauglitz et al. have used reflective interferometric spectroscopy (RIfS), a similar platform based on multiple white light reflections at thin transduction layers, to characterize biomolecule interactions in a multiplexed, high throughput format by attaching 96- and 384-well plates to the transducer slide. ${ }^{92}$ The varied applications of this RIfS platform include use as a screening tool for thrombin inhibitors and antibodies against triazine libraries. ${ }^{92,93}$

\section{BACKSCATTERING INTERFEROMETRY}

A new technique, backscattering interferometry (BSI), was originally used to measure small refractive index changes in fused-silica capillaries ${ }^{94}$ and has been developed in multiple configurations and for a wide array of applications. ${ }^{95-101}$ BSI has more recently been employed to study molecular interactions label-free and has proven to be a versatile and unique sensing technique in that it is the only interferometric sensor that can be used to investigate or quantify binding events in either a surface-immobilized format ${ }^{102-104}$ and/or free solution. ${ }^{105-110}$ This ability to measure interactions in a free-solution format sets BSI apart among interferometric techniques. The free-solution advantage not only eliminates the time and monetary costs related to immobilization strategies but also allows binding partners to be monitored entirely in their native state. Free-solution assays can be performed with little or no a priori knowledge of the interacting species, and it has been shown to be compatible with complex matrixes. ${ }^{105,106,108}$ Furthermore, because BSI is dually amenable to both free-solution and surface-immobilized formats, any contribution of immobilization to binding perturbation may be measured directly. Perhaps surprising in light of the platform's versatility is that BSI consists of an extremely simple optical train, requiring only a collimated coherent light source, a capillary or microfluidic chip (hemispherical or rectangular), and a detector.

At the heart of the interferometer is the chip, which serves as the optics. At the microchip, some of the light reflects off the surface, while the majority refracts into the chip substrate. At the fluid-substrate interface, a fraction of the light reflects back, while most of it refracts into the liquid media that contains the sample of interest. As the light passes through the fluid, its speed retards according to the fluid's refractive index. The light then reflects off the back surface of the chip, with some of it refracting back out of the channel and a large majority of it reflecting back into the channel and through the fluid media. This reflection/ refraction phenomenon continues for many cycles, with each cycle emitting and reflecting concordant fractions of the light. ${ }^{111}$ This "resonance phenomenon" results in a multipass configuration, increasing the effective optical path to many times the channel's diameter, and is responsible for BSI's extraordinary sensitivity. Reflected, refracted, and retarded beams recombine in a classical constructive and destructive manner to create a series of high contrast fringes extending above and below the chip. As discovered by Bornhop et al., fringes located in the near field, so-called backscatter direction, give the highest sensitivity to refractive index change, representing the most sensitive configuration for this interferometer. ${ }^{94}$ 
In the latest configuration of BSI (Figure 6), a microfluidic chip molded in polydimethylsulfoxide (PDMS) or etched in glass is employed. BSI utilizes a standard lowpower red helium-neon $(\mathrm{HeNe})$ laser $(\lambda=632.8 \mathrm{~nm})$ to illuminate the microfluidic channel (Figure 6A). While not absolutely necessary, the laser may be coupled to a collimating lens through a single-mode fiber. As the laser beam interacts with the fluid contained in the channel and reflects off of the channel surfaces, a set of high contrast interference fringes is produced and monitored in the direct backscatter region at relatively shallow angles (Figure 6). The spatial position of these fringes depends upon the refractive index (RI) of the fluid within the channel. The spatial change in fringe position is monitored using a CCD array in combination with Fourier analysis. ${ }^{104,112}$ A unique property of the fringes produced by BSI is that, when properly aligned, the fringes contain a single dominant frequency that remains constant while the fringes shift spatially with changes in RI of the fluid within the channel (Figure 6B). The use of the Fourier analysis allows for the quantification of the shift by locking in on the specific frequency of the fringes and calculating the phase information. The shift in the fringes is then quantified as a change in spatial phase, calculated in the Fourier domain. ${ }^{112}$ The RI of the fluid is sensitive to changes in conformation, charge distribution and hydration of the molecules within the solution. ${ }^{113}$ RI has also been shown to be affected by molecular structure, dipole moment, and polarizability. ${ }^{114,115}$ All of these properties are altered when two molecules bind to form a new compound, changing the RI of the solution and providing the means for BSI to measure the extent of the interaction. The universal signal allows BSI to be used to study a wide variety of interactions in an assortment of matrixes (Figure 7) without modifications to the instrument and no apparent sensitivity to the relative mass of the interacting partners.

It is important to note the refractive index sensitivity to temperature is a few parts in a thousand $\left(10^{-3}\right)$, and this represents a few millidegrees Celsius change when the refractive index change is less than a micro-RIU. Through the application of a Peltier thermostat controlling at $0.001{ }^{\circ} \mathrm{C}$ combined with the chip structure (microfluidic-based sensing), it has been possible to detect low $10^{-7}$ or mid $10^{-8}$ RIU changes, but temperature control is necessary for adequate operation. Additionally, as with all optical detection methods, particularly interferometers, it is critical to control the stability of the source so that timedependent variations do not adversely impact the S/N. In BSI, the contribution of the wavelength and pointing stability are also important because these parameters will impact the position of the beam and can lead to erroneous signals. Using a Fourier analysis to average the signal over many fringes allows us to filter out some of the inherent $\mathrm{HeNe}$ wavelength instabilities normally encountered in a direct measurement. Furthermore, employing a fiber coupler homogenizes the beam which ultimately reduces beam pointing instability generated beam shifts not originating from a binding event or RI change.

Originally, BSI facilitated interaction assays in the heterogeneous mode or utilized the immobilization of one binding partner onto the surface of a microfluidic chip molded in PDMS. ${ }^{103,104}$ In early experiments, streptavidin was immobilized onto the channel surface and the fringe pattern was measured before and after introducing biotin into the channel. A good correlation was found between the BSI molecular interaction signal and that reported by fluorescence. Next, a biotinylated protein- $\mathrm{A}\left(\mathrm{P}_{\mathrm{A}}\right)$ surface allowed the monitoring of 
reversible IgG- $\mathrm{P}_{\mathrm{A}}$ interactions with femtomole detection limits. ${ }^{104}$ New surface chemistry enabled a 2-fold improvement on detection limits of the protein A-IgG interaction without the use of a fluorescent label and also allowed monitoring of the hybridization of a complementary strand of DNA at concentrations ranging from $5 \mathrm{nM}$ to $500 \mathrm{mM}$ to a $30-\mathrm{mer}$ of mActin. Assuming 100\% surface coverage, the $3 \sigma$ limit of quantification was found to be 36 attomoles of DNA in the $500 \mathrm{pL}$ detection volume. Further experiments showed that a 3 base pair mismatch could be detected, evidenced by amarked decrease in binding signal from that of the original complementary strand; only $7 \%$ of the signal generated by the binding of the complementary strands was observed for the mismatched strand. ${ }^{103}$

The remarkable sensitivity of BSI was further demonstrated by expanding on these preliminary observations to study lectin-sugar binding. ${ }^{102}$ Since BSI is not dependent on a change in biolayer mass at the sensor surface, we were able to measure the binding of concanavilin A (con A) to mannose and glucose and the binding of a lectin isolated from Griffonia simplicifolia (BS-1) to galactose. Biotinylated lectins (proteins) were attached in functional form to the surface of glass microfluidic channels coated with extravidin by simple mixing. ${ }^{116}$ The binding of unmodified carbohydrates was monitored by BSI, and dose- response curves were used to generate values for association constants. Mannose and glucose were found to bind to the lectin concanavalin A with dissociation constants of $42 \pm$ $5 \mu \mathrm{M}$ and $155 \pm 88 \mu \mathrm{M}$, respectively; galactose bound to BS-1 lectin with a dissociation constant of $30.2 \pm 2.8 \mu \mathrm{M} .{ }^{102}$ This study is significant because it demonstrates that BSI uniquely allows quantification of a binding event for just one part in 1000 change in mass, allowing the protein to be tethered and the small molecule to be titrated. To our knowledge, this small molecule-protein assay has never been performed in this manner on another platform and represents a challenging assay for widely used label-free techniques.

In order to study multivalent interactions, the carbohydrate studies were then expanded to measure the binding of sugar-coated virus particles (cowpea mosaic virus (CPMV) and bacteriophage $\mathrm{Q} \beta$ virus-like particles). ${ }^{102} \mathrm{CPMV}$ particles with approximately 200 mannose molecules attached to the surface with three different linkers and were studied. The binding of these virus particles to immobilized Con A was monitored, and the saturation binding isotherms were plotted to determine the association constants. Comparison of the affinity of the particles to that of free mannose showed an average of a 100-fold increase in affinity on a per-glycan basis. Similarly, two different Q $\beta$ particles (450 and 470 mannose per particle) were studied, and the $K_{\mathrm{D}}$ values showed an approximately 220 -fold increase in affinity over that of free mannose on a per glycan basis. ${ }^{102}$ These studies illustrate that BSI has the potential to measure polymeric binding and the effects of cooperation.

Very recently, BSI was used to study the influence of surface immobilization and/or addition of a fluorophore on DNA hybridization. ${ }^{25}$ This work highlights the unique capability of BSI to perform assays in both the hetero- and homogeneous format, allowing one to quantify how a surface attachment strategy or fluorophore will influence the performance of the methodology (Figure 7A).

Likely, the most novel aspect of BSI is that it can be used to measure free-solution molecular interactions. Using a channel with a serpentine mixer and a restriction to mix the 
two interacting species on-chip, a stop-flow experiment can be performed label-free and in free solution to elicit real-time kinetic data (example in Figure 7B). Solutions may also be premixed off chip, enabling the determination of binding affinity and thermodynamics using an end-point format. ${ }^{106}$ Using these methods, systems reported were Protein $\mathrm{A}\left(\mathrm{P}_{\mathrm{A}}\right)$ which binds with high affinity to the $F_{C}$ region of several immunoglobulin $G(\operatorname{IgG})$ species, including human and rabbit; calmodulin $(\mathrm{CaM})$, the ubiquitous calcium-binding protein that can bind to and regulate a multitude of different protein targets; and the interaction between interleukin-2 (IL-2) and a monoclonal antibody, in this case in buffer and in cell-free media. Recent advancements of BSI have shown that molecular interaction assays can be performed utilizing exceedingly small amounts of sample at physiologically relevant concentrations, without the use of labels or surface immobilization, and in complex matrixes. For example, the entire CaM study (i.e., CaM-Ca ${ }^{2+}$, CaM-TFP, CaM-M13 peptide, and CaM-calcineurin) required the consumption of only about 200 picomoles or $3 \mathrm{mg}$ of $\mathrm{CaM}$, and each binding event only required $1 \mathrm{~min}$ for analysis. ${ }^{106}$

When the picomolar binding affinity of IL-2 in cell-free media was quantified, ${ }^{106}$ it was demonstrated that BSI has the potential to evaluate high-affinity interactions and is compatible with matrixes more complex than buffer. This unique ability to study freesolution binding in complex matrixes sets BSI apart.

Illustrating the extraordinary sensitivity of BSI, additional work with IL-2 calibrations was performed in solution using concentrations varying from 10 to $100 \mathrm{pM}$. Each concentration of IL-2 was introduced into the channel and allowed to pressure and temperature equilibrate, and the resulting signal was recorded. The average of three runs for each concentration produced a linear plot $\left(R^{2}=0.985\right)$ with a $3 \sigma$ detection limit of ca. $40 \mathrm{pM}$. At this detection limit, there are about 18 zeptomoles, 10800 molecules, or 270 attograms of protein in the probe volume $(490 \mathrm{pL}) .^{106}$

Recently published results indicate that BSI can be used to screen structurally destabilized mutants of the T4 lysozyme (T4L) against the small heat-shock protein (sHSP) $\alpha$-crystallin (Figure 7C). ${ }^{109}$ sHSPs constitute a superfamily of molecular chaperone proteins, which help other proteins to fold properly to prevent aggregation. Molecular chaperones have been linked to cataracts and neurodegenerative diseases such as Alzheimer's and Parkinson's. ${ }^{109,117,118}$ In these experiments, the differential binding of chaperone proteins to T4L mutants of varying stabilities was quantified, demonstrating the remarkable specificity of BSI in characterizing binding interactions. ${ }^{109}$

Because BSI works in free solution and with little a priori knowledge of the binding pair, the technique can be used to perform novel binding affinity determinations on uncharacterized molecules. This was illustrated with the affinity determination of the $\mathrm{p} 24$ protein with its newly synthesized monoclonal antibody. P24 is a core protein of the human immunodeficiency virus (HIV) and is one of the earliest indicators of the disease ${ }^{119}$ though as the disease progresses, the levels of the protein in the serumdecrease. ${ }^{120}$ As a result of its presence at the acute phase of HIV infection, quantification of p24 shows promise as an early detection and/or prognostic tool. The affinity of a monoclonal antibody (mAb) developed by the Centers for Disease Control and Prevention (CDC) against the p24 protein 
was determined by constructing an end point saturation binding curve utilizing BSI measurements. In this assay, p24 was held constant at $1 \mathrm{nM}$ and anti-p24 concentrations were varied from 0 to $800 \mathrm{nM}$. We calculated the $K_{\mathrm{D}}$ of this antigen-antibody pair, for the first time, to be $77.1 \mathrm{nM} \pm 16.7 \mathrm{nM}\left(R^{2}=0.99\right) .{ }^{121}$ The results of this affinity determination demonstrate that BSI may be used to study binding interactions with no prior knowledge of the dissociation constant $\left(K_{\mathrm{D}}\right)$.

Further, a collaboration with the Centers for Disease Control (CDC) allowed the investigation of the potential of BSI for serology testing. It has recently been found that BSI can detect the presence of antibodies against syphilis in free-solution measurements. ${ }^{108}$ End-point determinations were made, which entailed simply mixing off-line a known volume of one of three nontreponemal antigen preparations containing cardiolipin [one of three different proteins: synthetic multiple antigen peptide system (MAPS), bovine serum albumin, or chicken IGY antibody, covalently modified with cardiolipin] (at a known concentration) with a predetermined volume of the antiserum(antibody containing human serum). After equilibration, the mixture was introduced into BSI to obtain a reading of titer strength. Four human serum samples were provided and pretested for titer strength using the rapid plasmin reagin (RPR) test by the CDC. The samples were provided in blinded form (without the assay results) and were found to exhibit increasing BSI signals as shown (Figure 7D). After these results were obtained, our collaborators revealed the sample identities as one negative control and three samples derived from patients with increasing levels of infection (and therefore of circulating antibodies), exactly matching the BSI measurements. Next, the detection of antibodies in human sera against the treponemal 17 $\mathrm{kDa}$ lipoprotein, one of the proteins used in many commercial tests for syphilis, was demonstrated. In this case, the signal strength does not indicate disease progression, since the amount of treponemal antibody in sera is not proportional to the severity of the infection (i.e., the treponemal test is clinically nonquantitative). ${ }^{122}$ For these experiments, twelve different human sera samples (six positive and six negative) were evaluated using the same end point procedure. A statistically significant $\left(p=2 \times 10^{-6}\right)$ distinction between the positive and negative serum samples was found by BSI, illustrating its potential of serving as a reactive serum immunodiagnostic assay system.

Recently, BSI has been employed to help confirm the affinity and binding site of ferredoxin (Fd) to photosystem I (PSI) using cyanobacterial PSI as the model system. ${ }^{123}$ BSI found the affinity of the system to be $0.38 \mu \mathrm{M}$, which is in good agreement with previous measurements of $0.2-0.6 \mu \mathrm{M}$ found using electron transfer (ET) kinetics. ${ }^{124}$ The work also showed that binding occurred in a single-site manner, consistent with the current docking model. Work with a point mutation, which showed no binding, ${ }^{123}$ illustrated the necessity for the residue for the interaction to occur, further confirming the proposed binding site on the PSI. This work shows the utility of BSI not only to measure the affinity of binding but also to aid in biophysical mechanism studies aimed at determining of how and where the interaction occurs.

The inherent simplicity of BSI makes it a good candidate for miniaturization and the subsequent deployment in the near-patient or field setting. Since antibody-antigen-based sensing is widely used in these types of assays, we quantified the binding of five small 
molecules, including three amines of biological or metabolic relevance (serotonin, histamine, and dopamine), one modified amino acid (3-nitrotyrosine), and one molecule of interest in explosives detection (2,4,6-trinitrophenol, TNP). ${ }^{107}$ Each analyte was recognized by a commercially available antibody, either monoclonal (the first four compounds) or polyclonal (trinitrophenol). A compound of similar structure that was known not to bind to the antibody (or to bind with much lower affinity) was chosen as a negative control. In each case, a dosedependent change in refractive index was observed for the positive analyte, manifested as a shift in phase of the interference fringe pattern. Plots of these values against the concentration of analyte gave sigmoidal curves that fit well to a simple single-site binding model resulting in an equilibrium binding constant; an example is shown in Figure $7 \mathrm{E}$, along with the resulting $K_{\mathrm{d}}$ values, which are quite comparable to reported values obtained by more cumbersome techniques. Little or no BSI signal was observed for even the highest concentrations of the negative control compounds, showing that the BSI signal reflects specific interactions rather than a nonspecific binding interaction.

Very recently, it was shown that BSI can be used to quantify native, full length membraneassociated protein-ligand interactions. Membrane-associated proteins and their interactions are of paramount interest in the design of clinical therapies, accounting for almost $70 \%$ of existing drug candidate targets. ${ }^{125,126}$ To date, it has been difficult to perform direct binding assays on cellular membranes except by downstream signal transduction or the use of isotope labeling methods. In the paper by Baksh et. al., it was shown that stable full-length functional membrane proteins, from both natural and recombinant sources, can be made into proteoliposomes, ${ }^{127,128}$ facilitating label-free, free solution binding assays with BSI. ${ }^{107}$

Among the systems investigated, we looked at (A) the transmembrane protein fatty acid amide hydrolase (FAAH) ${ }^{127,129,130}$ incorporated into small unilamellar vesicles (SUV's) and the binding to several small molecule inhibitors (OL-135, JGII-145, and FAR-1-216), (B) the CXCR4 receptor binding the stromal cell-derived factor $1 a$, and (C) a difficult to isolate and purify target, the heterodimeric ${ }^{131} \gamma$-amino-butyric acid (GABA) receptor ${ }^{132}$ binding to several small molecule ligands ( $R$-baclofen, GABA, SKF-97541, and CGP-54626). This system was studied directly as intact membranes from Chinese hamster ovary $(\mathrm{CHO})$ cells genetically modified to overexpress the $\mathrm{B}(1 \mathrm{~b})$ and $\mathrm{B} 2$ components of the $\mathrm{GABA}_{\mathrm{B}}$ receptor. Plots of signal vs concentration of ligand (example in Figure 7F) gave sigmoidal curves that fit well to a simple single-site binding model, resulting in equilibrium binding constants which are quite comparable to reported values. ${ }^{133-137}$ Little or no BSI signal was observed for even the highest concentrations of a negative control compound (Lalanine and cholesterol), again showing that the BSI signal reflects specific interactions.

A rather unique application of BSI was recently published in Organic Letters ${ }^{138}$ showing that it is not just a "Bio"-sensor and that hydrogen bond forming and breaking can be monitored. This example is important to the field of chemical catalysis and could pave the way for the development of a universally applicable device, maybe the molecular interaction photometer. 


\section{SUMMARY}

As shown, interferometry continues to be a powerful approach to biosensing. The methods discussed or reported elsewhere have realized advantages including label-free measurements, high-throughput microarray compatibility, microfluidics-free platforms, single-molecule detection, ultrasmall sample volume analysis, and free-solution measurements. These advances represent significant breakthroughs for drug discovery and diagnostics, as well as other biochemical and environmental applications. Additionally, many of these techniques have the potential to combine several of these important features which could lead to a paradigm shift in biosensing. Such a shift is actually underway as we prepare this report. We predict the pace of transition will be accelerated by the desire to improve assay methodology, discover new therapies, and perform systems biology, as well as aid the rapid advancement of miniaturized optics and electronics. It is our belief that the sensitivity and label-free nature of interferometry will lead to deployment into the nearpatient setting, enabling personalized medicine to be realized and having an extraordinary impact on human health.

\section{Acknowledgments}

The authors are grateful for support for this work provided by the National Science Foundation (CHE-0848788) and the Vanderbilt University Institute of Chemical Biology.

\section{References}

1. Herschel W. Philos Trans R Soc, London. 1805; 95:31-64.

2. Baldwin JE, Haniff CA. Philos Trans: Math, Phys Eng Sci. 2002; 360:969-986.

3. Michelson AA, Pease FG. Astrophys J. 1921; 53:249-259.

4. Bruning JH, Herriott DR, Gallaghe Je, Rosenfel Dp, White AD, Brangacc DJ. Appl Opt. 1974; 13:2693-2703. [PubMed: 20134757]

5. Scudieri F. Appl Opt. 1980; 19:404-408. [PubMed: 20216862]

6. van Deelen W, Nisenson P. Appl Opt. 1969; 8:951-955. [PubMed: 20072353]

7. Goldstein RM, Zebker HA. Nature. 1987; 328:707-709.

8. Graber HC, Thompson DR, Carande RE. J Geophys Res, [Oceans]. 1996; 101:25813-25832.

9. Massonnet D, Rossi M, Carmona C, Adragna F, Peltzer G, Feigl K, Rabaute T. Nature. 1993; 364:138-142.

10. Vincent P, Larsen S, Galloway D, Laczniak RJ, Walter WR, Foxall W, Zucca JJ. Geophys Res Lett. 2003; 30:2141-2145.

11. Ince R, Narayanaswamy R. Anal Chim Acta. 2006; 569:1-20.

12. Cooper MA. Drug Discovery Today. 2006; 11:1061-1067. [PubMed: 17129824]

13. Goh JB, Loo RW, Goh MC. Sens Actuators, B: Chem. 2005; 106:243-248.

14. Lee M, Fauchet PM. Optics Express. 2007; 15:4530-4535. [PubMed: 19532700]

15. Lu JH, Strohsahl CM, Miller BL, Rothberg LJ. Anal Chem. 2004; 76:4416-4420. [PubMed: 15283581]

16. Mace CR, Striemer CC, Miller BL. Anal Chem. 2006; 78:5578-5583. [PubMed: 16878898]

17. Qavi AJ, Washburn AL, Byeon JY, Bailey RC. Anal Bioanal Chem. 2009; 394:121-135. [PubMed: 19221722]

18. Fan XD, White IM, Shopoua SI, Zhu HY, Suter JD, Sun YZ. Anal Chim Acta. 2008; 620:8-26. [PubMed: 18558119]

19. Vollmer F, Arnold S. Nat Methods. 2008; 5:591-596. [PubMed: 18587317] 
20. Washburn AL, Gunn LC, Bailey RC. Anal Chem. 2009; 81:9499-9506. [PubMed: 19848413]

21. Wang X, Zhao M, Nolte DD, Ratliff TL. Biosens Bioelectron. 2011; 26:1871-1875. [PubMed: 20236816]

22. Bailey RC, Washburn AL, Qavi AJ, Iqbal M, Gleeson M, Tybor F, Gunn LC. Proc SPIE. 2009; 7220:72200N. doi:72210.71117/72212.809819.

23. Ozkumur E, Ahn S, Yalcin A, Lopez CA, Cevik E, Irani RJ, DeLisi C, Chiari M, Unlu MS. Biosens Bioelectron. 2010; 25:1789-1795. [PubMed: 20097056]

24. Armani AM, Kulkarni RP, Fraser SE, Flagan RC, Vahala KJ. Science. 2007; 317:783-787. [PubMed: 17615303]

25. Pesciotta EN, Bornhop DJ, Robert A, Flowers I. Chem-Asian J. 2011; 6:70-73. [PubMed: 21082726]

26. Proll G, Markovic G, Steinle L, Gauglitz G. Methods Mol Biol. 2009; 503:167-178. [PubMed: 19151940]

27. Passaro VMN, Dell'Olio F, Casamassima B, De Leonardis F. Sensors. 2007; 7:508-536.

28. Densmore A, Vachon M, Xu DX, Janz S, Ma R, Li YH, Lopinski G, Delage A, Lapointe J, Luebbert CC, Liu QY, Cheben P, Schmid JH. Opt Lett. 2009; 34:3598-3600. [PubMed: 19953132]

29. Brosinger F, Freimuth H, Lacher M, Ehrfeld W, Gedig E, Katerkamp A, Spener F, Cammann K. Sens Actuators, B: Chem. 1997; 44:350-355.

30. Prieto F, Sepulveda B, Calle A, Llobera A, Dominguez C, Abad A, Montoya A, Lechuga LM. Nanotechnology. 2003; 14:907-912.

31. Prieto F, Sepulveda B, Calle A, Llobera A, Dominguez C, Lechuga LM. Sens Actuators, B: Chem. 2003; 92:151-158.

32. Schipper EF, Brugman AM, Dominguez C, Lechuga LM, Kooyman RPH, Greve J. Sens Actuators, B: Chem. 1997; 40:147-153.

33. Prabhathan P, Murukeshan VM, Jing Z, Ramana PV. Opt Express. 2009; 17:15330-15341. [PubMed: 19688011]

34. Hradetzky D, Mueller C, Reinecke H. J Opt A: Pure Appl Opt. 2006; 8:S360-S364.

35. Schmitt K, Schirmer B, Hoffmann C, Brandenburg A, Meyrueis P. Biosens Bioelectron. 2007; 22:2591-2597. [PubMed: 17125988]

36. Ymeti A, Kanger JS, Greve J, Lambeck PV, Wijn R, Heideman RG. Appl Opt. 2003; 42:56495660. [PubMed: 14528926]

37. Schneider BH, Edwards JG, Hartman NF. Clin Chem. 1997; 43:1757-1763. [PubMed: 9299972]

38. Schneider BH, Dickinson EL, Vach MD, Hoijer JV, Howard LV. Biosens Bioelectron. 2000; 15:13-22. [PubMed: 10826639]

39. Schneider BH, Dickinson EL, Vach MD, Hoijer JV, Howard LV. Biosens Bioelectron. 2000; 15:597-604. [PubMed: 11213220]

40. Halpern AR, Nishi N, Wen J, Yang F, Xiang CX, Penner RM, Corn RM. Anal Chem. 2009; 81:5585-5592. [PubMed: 19537714]

41. Chen YL, Kung SC, Taggart DK, Halpern AR, Penner RM, Corn RM. Anal Chem. 2010; 82:33653370. [PubMed: 20337428]

42. St John PM, Davis R, Cady N, Czajka J, Batt CA, Craighead HG. Anal Chem. 1998; 70:11081111. [PubMed: 9530002]

43. Barrios CA, Zhenhe C, Navarro-Villoslada F, López-Romero D, Moreno-Bondi MC. Biosens Bioelectron. 2011; 26:2801- 2804. [PubMed: 21131191]

44. Cleverley S, Chen I, Houle JF. J Chromatogr, B: Anal Technol Biomed Life Sci. 2010; 878:264270.

45. Houle J, Kumaraswamy S. Nat Methods. 2007; 4:i-ii.

46. Swann MJ, Peel LL, Carrington S, Freeman NJ. Anal Biochem. 2004; 329:190-198. [PubMed: 15158477]

47. Lin SM, Lee CK, Lin YH, Lee SY, Sheu BC, Tsai JC, Hsu SM. Biosens Bioelectron. 2006; 22:715-721. [PubMed: 16569500] 
48. Ricard-Blum S, Peel LL, Ruggiero F, Freeman NJ. Anal Biochem. 2006; 352:252-259. [PubMed: 16545768]

49. Wang J, Xu XW, Zhang ZX, Yang F, Yang XR. Anal Chem. 2009; 81:4914-4921. [PubMed: 19518147]

50. Wang JA, Coffey PD, Swann MJ, Yang F, Lu JR, Yang XR. Anal Chem. 2010; 82:5455-5462. [PubMed: 20524624]

51. Baird CL, Myszka DG. J Mol Recognit. 2001; 14:261-268. [PubMed: 11746946]

52. See, for example, www.farfield-group.com.

53. Lee TH, Hall KN, Swann MJ, Popplewell JF, Unabia S, Park Y, Hahm KS, Aguilar MI. Biochim Biophys Acta, Biomembr. 2010; 1798:544-557.

54. De Vos K, Bartolozzi I, Schacht E, Bienstman P, Baets R. Opt Express. 2007; 15:7610-7615. [PubMed: 19547087]

55. Xu DX, Densmore A, Delage A, Waldron P, McKinnon R, Janz S, Lapointe J, Lopinski G, Mischki T, Post E, Cheben P, Schmid JH. Opt Express. 2008; 16:15137-15148. [PubMed: 18795053]

56. Luchansky MS, Bailey RC. Anal Chem. 2010; 82:1975-1981. [PubMed: 20143780]

57. Qavi AJ, Bailey RC. Angew Chem, Int Ed. 2010; 49:4608-4611.

58. Washburn AL, Luchansky MS, Bowman AL, Bailey RC. Anal Chem. 2010; 82:69-72. [PubMed: 20000326]

59. Iqbal M, Gleeson MA, Spaugh B, Tybor F, Gunn WG, Hochberg M, Baehr-Jones T, Bailey RC, Gunn LC. IEEE J Sel Top Quantum Electron. 2010; 16:654-661.

60. Luchansky MS, Washburn AL, Martin TA, Iqbal M, Gunn LC, Bailey RC. Biosens Bioelectron. 2010; 26:1283-1291. [PubMed: 20708399]

61. Gan QQ, Gao YK, Bartoli FJ. Opt Express. 2009; 17:20747-20755. [PubMed: 19997306]

62. Kim DK, Kerman K, Saito M, Sathuluri RR, Endo T, Yamamura S, Kwon YS, Tamiya E. Anal Chem. 2007; 79:1855-1864. [PubMed: 17261024]

63. Nikitin PI, Grigorenko AN, Beloglazov AA, Valeiko MV, Savchuk AI, Savchuk OA, Steiner G, Kuhne C, Huebner A, Salzer R. Sens Actuators, A: Phys. 2000; 85:189-193.

64. Wu CM, Jian ZC, Joe SF, Chang LB. Sens Actuators, B: Chem. 2003; 92:133-136.

65. Alieva E, Konopsky VN. Sens Actuators, B: Chem. 2004; 99:90-97.

66. Ng SP, Wu CML, Wu SY, Ho HP, Kong SK. Biosens Bioelectron. 2010; 26:1593-1598. [PubMed: 20800466]

67. Ng S-P, Wu C-ML, Wu S-Y, Ho H-P, Kong S-K. Proc SPIE. 2011; 7911:79110C. 79110.71117/79112.874108.

68. Gauglitz G. Anal Bioanal Chem. 2005; 381:141-155. [PubMed: 15700161]

69. Dancil KPS, Greiner DP, Sailor MJ. J Am Chem Soc. 1999; 121:7925-7930.

70. Lin VSY, Motesharei K, Dancil KPS, Sailor MJ, Ghadiri MR. Science. 1997; 278:840-843. [PubMed: 9346478]

71. Mun KS, Alvarez SD, Choi WY, Sailor MJ. ACS Nano. 2010; 4:2070-2076. [PubMed: 20356100]

72. Pan SL, Rothberg LJ. Nano Lett. 2003; 3:811-814.

73. Alvarez SD, Li CP, Chiang CE, Schuller IK, Sailor MJ. ACS Nano. 2009; 3:3301-3307. [PubMed: 19719156]

74. Ouyang H, DeLouise LA, Miller BL, Fauchet PM. Anal Chem. 2007; 79:1502-1506. [PubMed: 17241093]

75. Li YY, Cunin F, Link JR, Gao T, Betts RE, Reiver SH, Chin V, Bhatia SN, Sailor MJ. Science. 2003; 299:2045-2047. [PubMed: 12663921]

76. Latterich M, Corbeil J. Proteome Sci. 2008; 610.1186/1477-5956-6-31

77. Sanchez AB, Nguyen T, Dema-Ala R, Kummel AC, Kipps TJ, Messmer BT. Cancer Chemother Pharmacol. 2010; 66:919-925. [PubMed: 20087593]

78. Sperandio S, Tardito S, Surzycki A, Latterich M, Belle Id. FEBS Lett. 2009; 583:2165-2170. [PubMed: 19508870]

79. See, for example, www.siliconkinetics.com. 
80. Varma MM, Inerowicz HD, Regnier FE, Nolte DD. Biosens Bioelectron. 2004; 19:1371-1376. [PubMed: 15093207]

81. Varma MM, Nolte DD, Inerowicz HD, Regnier FE. Opt Lett. 2004; 29:950-952. [PubMed: 15143637]

82. Zhao M, Nolte D, Cho WR, Regnier F, Varma M, Lawrence G, Pasqua J. Clin Chem. 2006; 52:2135-2140. [PubMed: 16990417]

83. Wang XF, Zhao M, Nolte DD. Anal Bioanal Chem. 2009; 393:1151-1156. [PubMed: 18791869]

84. See, for example, www.fortebio.com.

85. Do T, Ho F, Heidecker B, Witte K, Chang L, Lerner L. Protein Expression Purif. 2008; 60:147150.

86. Abdiche Y, Malashock D, Pinkerton A, Pons J. Anal Biochem. 2008; 377:209-217. [PubMed: 18405656]

87. Horner SR, Mace CR, Rothberg LJ, Miller BL. Biosens Bioelectron. 2006; 21:1659-1663. [PubMed: 16154335]

88. Gao T, Rothberg LJ. Anal Chem. 2007; 79:7589-7595. [PubMed: 17845004]

89. Zubritsky E. Anal Chem. 2007; 79:7941-7941.

90. Ozkumur E, Needham JW, Bergstein DA, Gonzalez R, Cabodi M, Gershoni JM, Goldberg BB, Unlu MS. Proc Natl Acad Sci USA. 2008; 105:7988-7992. [PubMed: 18523019]

91. Özkumur E, Yalçin A, Cretich M, Lopez CA, Bergstein DA, Goldberg BB, Chiari M, Ünlü MS. Biosens Bioelectron. 2009; 25:167-172. [PubMed: 19628383]

92. Birkert O, Gauglitz G. Anal Bioanal Chem. 2002; 372:141-147. [PubMed: 11939184]

93. Birkert O, Tunnernann R, Jung G, Gauglitz G. Anal Chem. 2002; 74:834-840. [PubMed: 11866064]

94. Bornhop DJ. Appl Opt. 1995; 34:3234-3239. [PubMed: 21052128]

95. Markov DA, Bornhop DJ. Fresenius J Anal Chem. 2001; 371:234-237. [PubMed: 11678197]

96. Markov DA, Dotson S, Wood S, Bornhop DJ. Electrophoresis. 2004; 25:3805-3809. [PubMed: 15565690]

97. Sorensen HS, Pranov H, Larsen NB, Bornhop DJ, Andersen PE. Anal Chem. 2003; 75:1946-1953. [PubMed: 12713055]

98. Swinney K, Bornhop DJ. Electrophoresis. 2001; 22:2032- 2036. [PubMed: 11465503]

99. Swinney K, Bornhop DJ. Electrophoresis. 2002; 23:613-620. [PubMed: 11870773]

100. Wang ZL, Bornhop DJ. Anal Chem. 2005; 77:7872-7877. [PubMed: 16351132]

101. Wang ZL, Swinney K, Bornhop DJ. Electrophoresis. 2003; 24:865-873. [PubMed: 12627449]

102. Kussrow A, Kaltgrad E, Wolfenden ML, Cloninger MJ, Finn MG, Bornhop DJ. Anal Chem. 2009; 81:4889-4897. [PubMed: 19462965]

103. Latham JC, Markov DA, Sorensen HS, Bornhop DJ. Angew Chem, Int Ed. 2006; 45:955-958.

104. Markov DA, Swinney K, Bornhop DJ. J Am Chem Soc. 2004; 126:16659-16664. [PubMed: 15600372]

105. Baksh MM, Kussrow AK, Mileni M, Finn MG, Bornhop DJ. Nat Biotechnol. 2011; 29:357-360. [PubMed: 21399645]

106. Bornhop DJ, Latham JC, Kussrow A, Markov DA, Jones RD, Sorensen HS. Science. 2007; 317:1732-1736. [PubMed: 17885132]

107. Kussrow A, Baksh MM, Bornhop DJ, Finn MG. ChemBioChem. 2011; 12:367-370. [PubMed: 21290534]

108. Kussrow A, Enders CS, Castro AR, Cox DL, Ballard RC, Bornhop DJ. Analyst. 2010; 135:15351537. [PubMed: 20414494]

109. Latham JC, Stein RA, Bornhop DJ, Mchaourab HS. Anal Chem. 2009; 81:1865-1871. [PubMed: 19178288]

110. Morcos EF, Kussrow A, Enders C, Bornhop D. Electrophoresis. 2010; 31:3691-3695. [PubMed: 20972990]

111. Swinney K, Markov D, Bornhop DJ. Anal Chem. 2000; 72:2690-2695. [PubMed: 10905294]

112. Markov D, Begari D, Bornhop DJ. Anal Chem. 2002; 74:5438-5441. [PubMed: 12403605] 
113. Sota H, Hasegawa Y, Iwakura M. Anal Chem. 1998; 70:2019-2024. [PubMed: 9608841]

114. Elkashef H. Opt Mater. 1997; 8:175-183.

115. Maroulis G, Xenides D, Hohm U, Loose A. J Chem Phys. 2001; 115:7957-7967.

116. Taguchi T, Takeyama H, Matsunaga T. Biosens Bioelectron. 2005; 20:2276-2282. [PubMed: 15797326]

117. Bucciantini M, Giannoni E, Chiti F, Baroni F, Formigli L, Zurdo JS, Taddei N, Ramponi G, Dobson CM, Stefani M. Nature. 2002; 416:507-511. [PubMed: 11932737]

118. Forman MS, Lee VMY, Trojanowski JQ. Trends Neurosci. 2003; 26:407-410. [PubMed: 12900170]

119. Iweala OI. Contraception. 2004; 70:141-147. [PubMed: 15288219]

120. Bhardwaj D, Bhatt S, Khamar BM, Modi RI, Ghosh PK. Curr Sci. 2006; 91:913-917.

121. Kussrow A, Enders CS, Morcos EF, Bornhop DJ. J Assoc Lab Autom. 2009; 14:341-347.

122. Larsen, SA.; Pope, V.; Johnson, RE., Jr; Kennedy, EJ., editors. A Manual of Tests for Syphilis. 9. American Public Health Association; Washington D.C: 1998.

123. Setif P, Harris N, Lagoutte B, Dotson S, Weinberger SR. J Am Chem Soc. 2010; 132:1062010622. [PubMed: 20681677]

124. Setif P. Biochim Biophys Acta, Bioenerg. 2001; 1507:161-179.

125. Krummel MF, Davis MM. Curr Opin Immunol. 2002; 14:66-74. [PubMed: 11790534]

126. Overington JP, Al-Lazikani B, Hopkins AL. Nat Rev Drug Discovery. 2006; 5:993-996.

127. Bracey MH, Hanson MA, Masuda KR, Stevens RC, Cravatt BF. Science. 2002; 298:1793-1796. [PubMed: 12459591]

128. Jass J, Tjarnhage T, Puu G. Biophys J. 2000; 79:3153-3163. [PubMed: 11106620]

129. Cravatt BF, Prosperogarcia O, Siuzdak G, Gilula NB, Henriksen SJ, Boger DL, Lerner RA. Science. 1995; 268:1506-1509. [PubMed: 7770779]

130. Devane WA, Hanus L, Breuer A, Pertwee RG, Stevenson LA, Griffin G, Gibson D, Mandelbaum A, Etinger A, Mechoulam R. Science. 1992; 258:1946-1949. [PubMed: 1470919]

131. Pin JP, Kniazeff J, Binet V, Liu JF, Maurel D, Galvez T, Duthey W, Havlickova M, Blahos J, Prezeau L, Rondard P. Biochem Pharmacol. 2004; 68:1565-1572. [PubMed: 15451400]

132. Urwyler S, Mosbacher J, Lingenhoehl K, Heid J, Hofstetter K, Froestl W, Bettler B, Kaupmann K. Mol Pharmacol. 2001; 60:963-971. [PubMed: 11641424]

133. Boger DL, Miyauchi H, Du W, Hardouin C, Fecik RA, Cheng H, Hwang I, Hedrick MP, Leung D, Acevedo O, Guimaraes CRW, Jorgensen WL, Cravatt BF. J Med Chem. 2005; 48:1849-1856. [PubMed: 15771430]

134. Froestl W, Mickel SJ, Hall RG, Vonsprecher G, Strub D, Baumann PA, Brugger F, Gentsch C, Jaekel J, Olpe HR, Rihs G, Vassout A, Waldmeier PC, Bittiger H. J Med Chem. 1995; 38:32973312. [PubMed: 7650684]

135. Garfunkle J, Ezzili C, Rayl TJ, Hochstatter DG, Hwang I, Boger DL. J Med Chem. 2008; 51:4392-4403. [PubMed: 18630870]

136. Kaupmann K, Huggel K, Heid J, Flor PJ, Bischoff S, Mickel SJ, McMaster G, Angst C, Bittiger H, Froestl W, Bettler B. Nature. 1997; 386:239-246. [PubMed: 9069281]

137. Romero FA, Du W, Hwang I, Rayl TJ, Kimball FS, Leung D, Hoover HS, Apodaca RL, Breitenbucher JG, Cravatt BF, Boger DL. J Med Chem. 2007; 50:1058-1068. [PubMed: 17279740]

138. Pesciotta EN, Bornhop DJ, Flowers RA. Org Lett. 2011; 13:2654-2657. [PubMed: 21510617]

\section{Biographies}

Dr. Amanda Kussrow received her B.S. in Chemistry summa cum laude from Stevenson University. She earned her Ph.D. in Analytical Chemistry under the direction of Dr. Darryl Bornhop, at Vanderbilt University, where she received a GAANN Fellowship and was a trainee in the Chemical Biology Interface Program. Currently, she is a postdoctoral fellow at 
Vanderbilt University and consults for parties in the industrial sector. Dr. Kussrow's research focuses on backscattering interferometry and on the development and application of the technology.

Carolyn S. Enders received her B.S. in Biochemistry summa cum laude from Berry College in Rome, GA. She received her M.S. in Chemistry from Vanderbilt University, focusing on molecular interaction studies using backscattering interferometry under Professor Darryl J. Bornhop. Carolyn is also a registered nurse and is currently an MSN candidate at the Vanderbilt University School of Nursing.

Dr. Darryl J. Bornhop received his B.S. in chemistry and his M.A. in Environmental Chemistry from the University of Missouri in Columbia. He earned his Ph.D. in Analytical Chemistry under the direction of Dr. Norman J. Dovichi at the University of Wyoming and the University of Alberta. After working in the private sector in a variety of capacities from principal scientist at Spectra Physics Inc. to Vice President for R\&D at MediVisions Inc., he joined the faculty at Texas Tech University becoming Professor of Chemistry and Biochemistry and Research Professor at the Southwest Cancer Center. Dr. Bornhop is currently Professor of Chemistry at Vanderbilt University and a core member of the Vanderbilt Institute for Chemical Biology and the Vanderbilt-Ingram Cancer Center. His research interests are interdisciplinary and include Chemical Biology, Chemical Analysis, Molecular Imaging, Nanoscale Sensing, and the deployment of Personalized Medicine. 

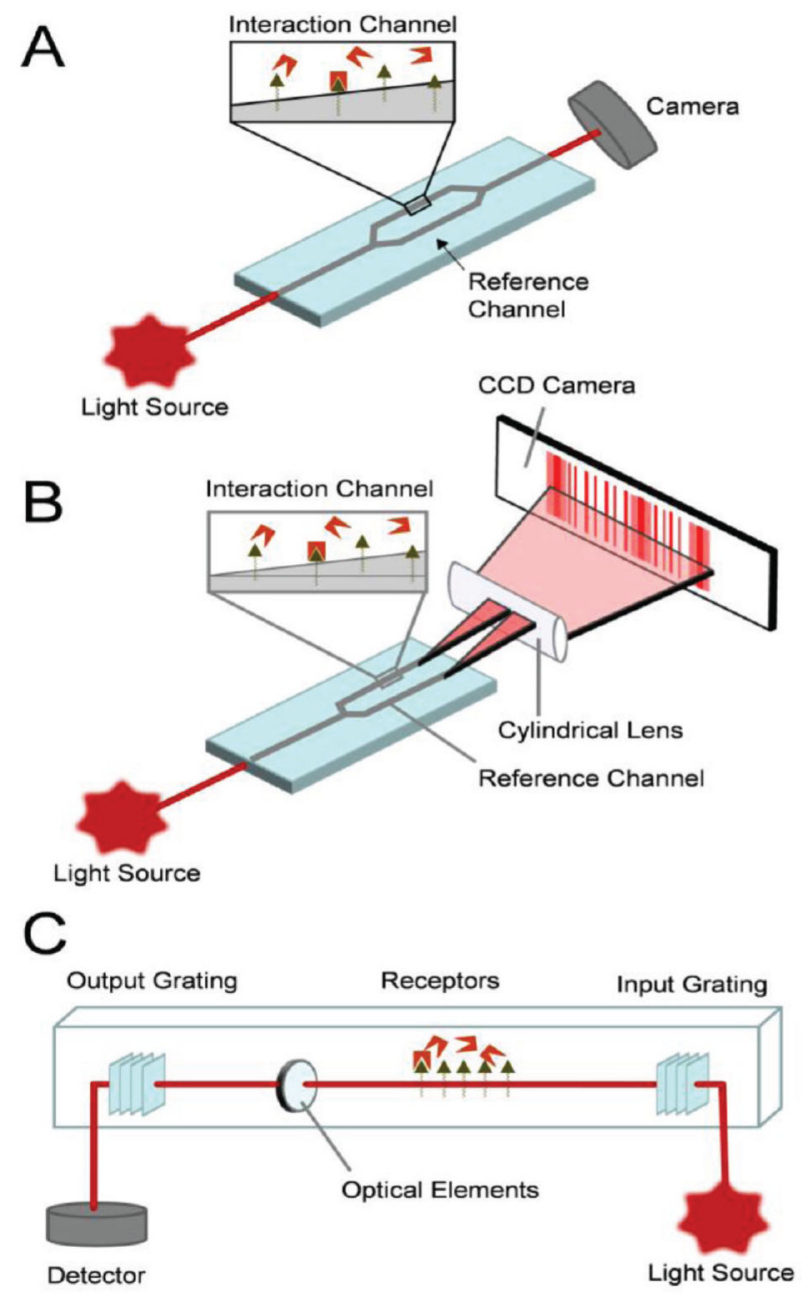

Figure 1.

Block diagrams of (A) a Mach-Zehnder interferometer (MZI), (B) a Young interferometer (YI), and (C) a Hartman interferometer (HI). 

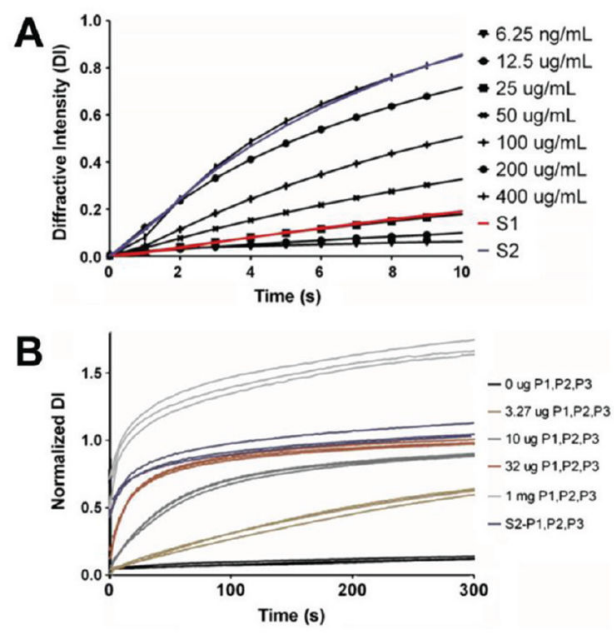

C Transmission

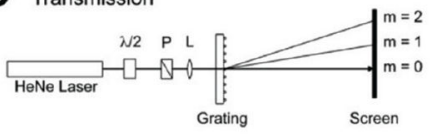

External Reflection

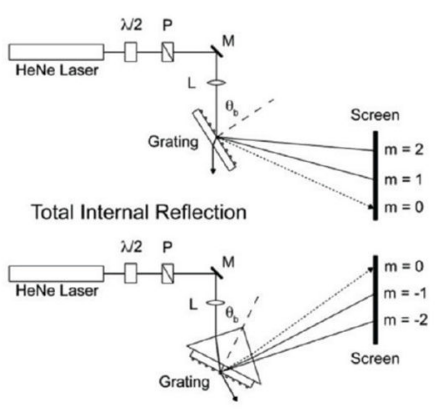

Figure 2.

(A) Overlay of normalized analyte binding zones for human IgG captured by immobilized Protein A. Reprinted from ref 44, Copyright 2010, with permission from Elsevier. (B) Overlay of representative sample of normalized analyte binding zones for quantitation of a $46 \mathrm{kDa}$ fusion protein. Reprinted from ref 44, Copyright 2010, with permission from Elsevier. (C) Schematic diagram of the three geometries that can be used to obtain diffraction images. Reprinted from ref 40. Copyright 2009 American Chemical Society. 

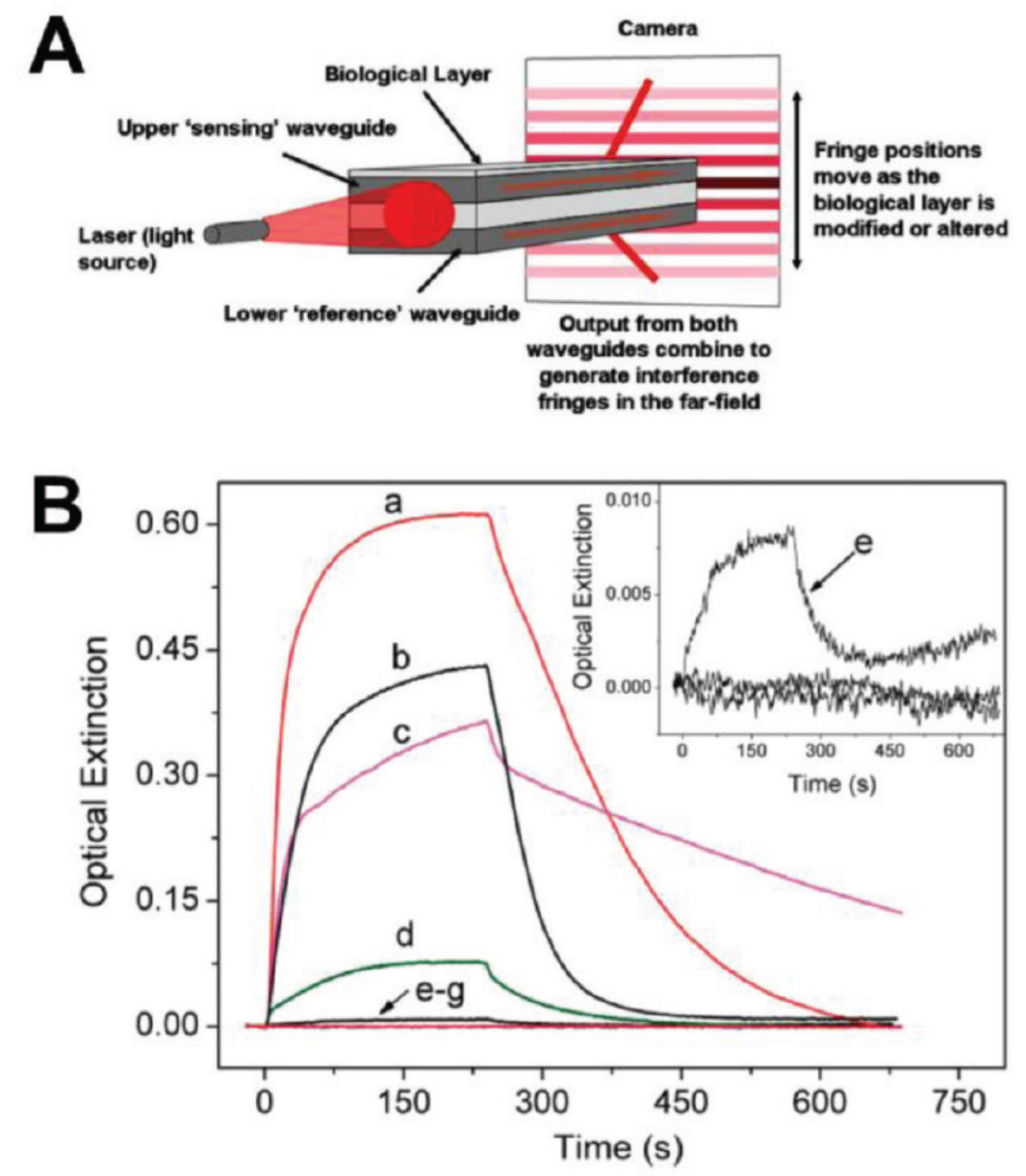

Figure 3.

(A) Schematic of the dual-polarization interferometer. Reprinted from ref 46, Copyright 2004, with permission from Elsevier. (B) The optical extinction during the injection of 10 $\mu \mathrm{M}$ methylene blue over the DNA/PEI layer (a), the DNA/amino layer (b), bare chip surface (d), the PEI surface (e), and the amino surface (f), or $10 \mu \mathrm{M}$ mitoxantrone over the DNA/ amino layer (c) and the amino surface $(\mathrm{g})$. The RI and mass of the DNA layer on PEI: 1.382, $2.05 \mathrm{ng} / \mathrm{mm}^{2}$; the RI and mass of the DNA layer on amino surface: $1.379,1.36 \mathrm{ng} / \mathrm{mm}^{2}$. Reprinted from ref 50. Copyright 2010 American Chemical Society. 
A
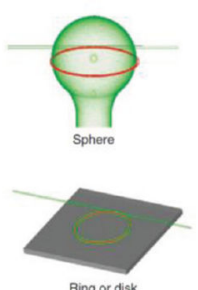
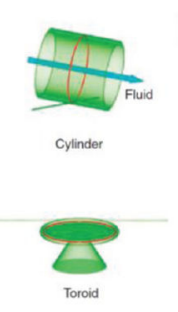

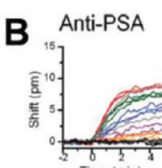

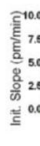
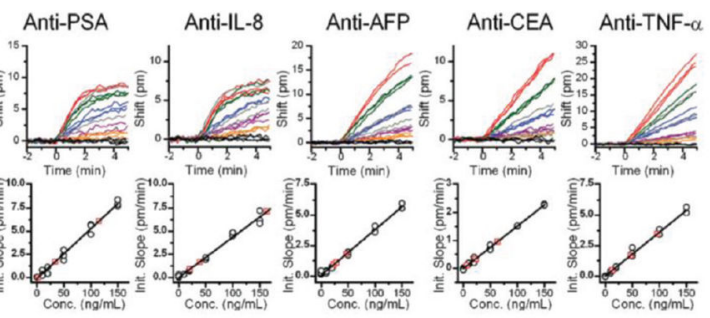

Figure 4.

(A) Waveguide microresonator geometries. The resonance path is highlighted in red; blue indicates microfluidic flow. Reprinted by permission from Macmillian Publishers Ltd:

Nature Methods, ref 19, Copyright 2008. (B) Real time response curves for 5 representative sensors (out of 20 total) and corresponding calibration curves based on the initial slope of the response curve. For the response curves, the colored lines represent the following concentrations of the antibody-specific antigen: red, $150 \mathrm{ng} / \mathrm{mL}$; green, $100 \mathrm{ng} / \mathrm{mL}$; blue, 50 $\mathrm{ng} / \mathrm{mL}$; purple, $20 \mathrm{ng} / \mathrm{mL}$; orange, $10 \mathrm{ng} / \mathrm{mL}$; black, $0 \mathrm{ng} / \mathrm{mL}$; gray, unknown solutions. For the calibration curves, black circles are the calibration points and red squares represent the unknowns. Reprinted from ref 58. Copyright 2010 American Chemical Society. 


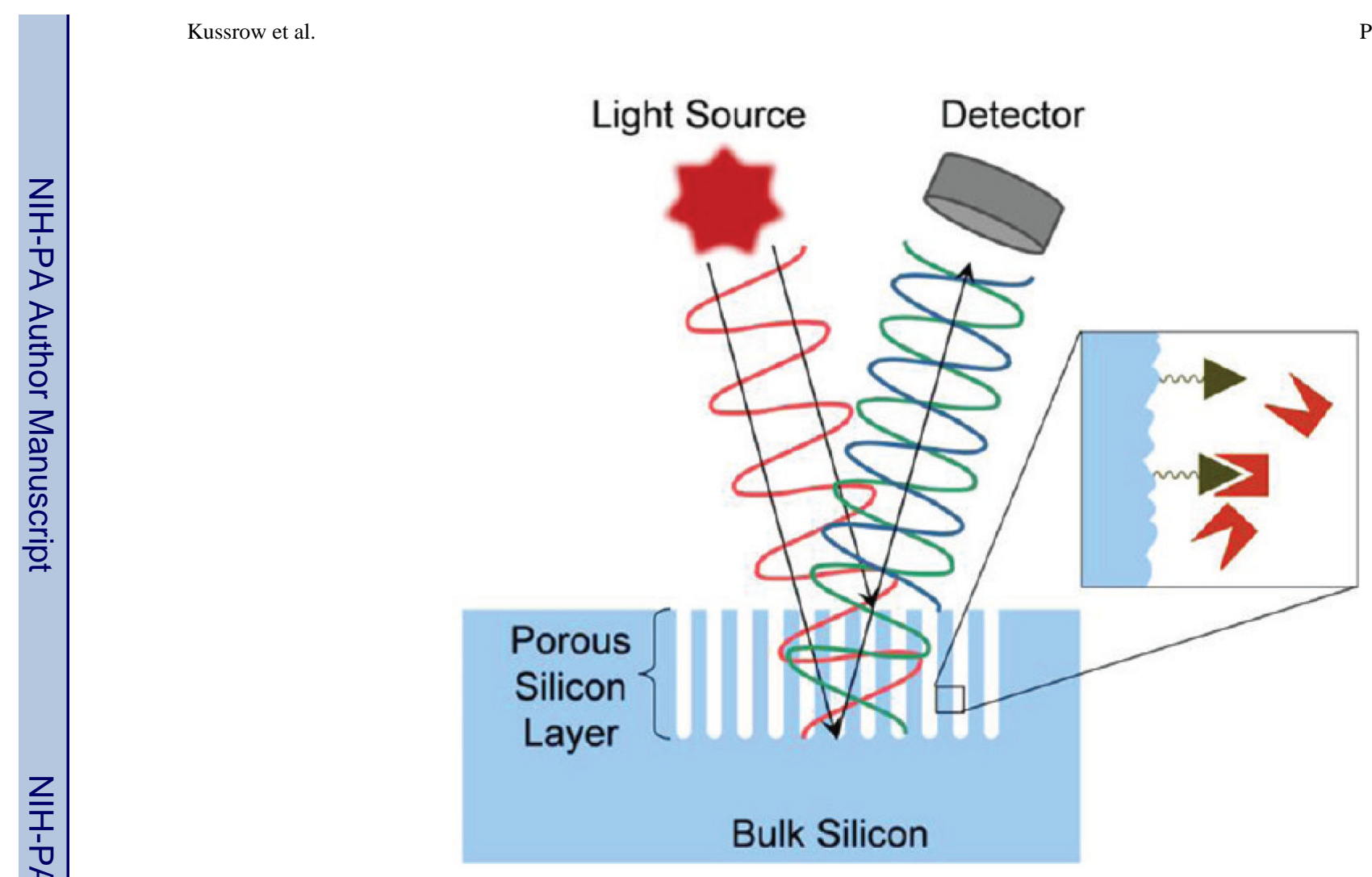

Figure 5.

Block diagram of a porous silicon sensor. 


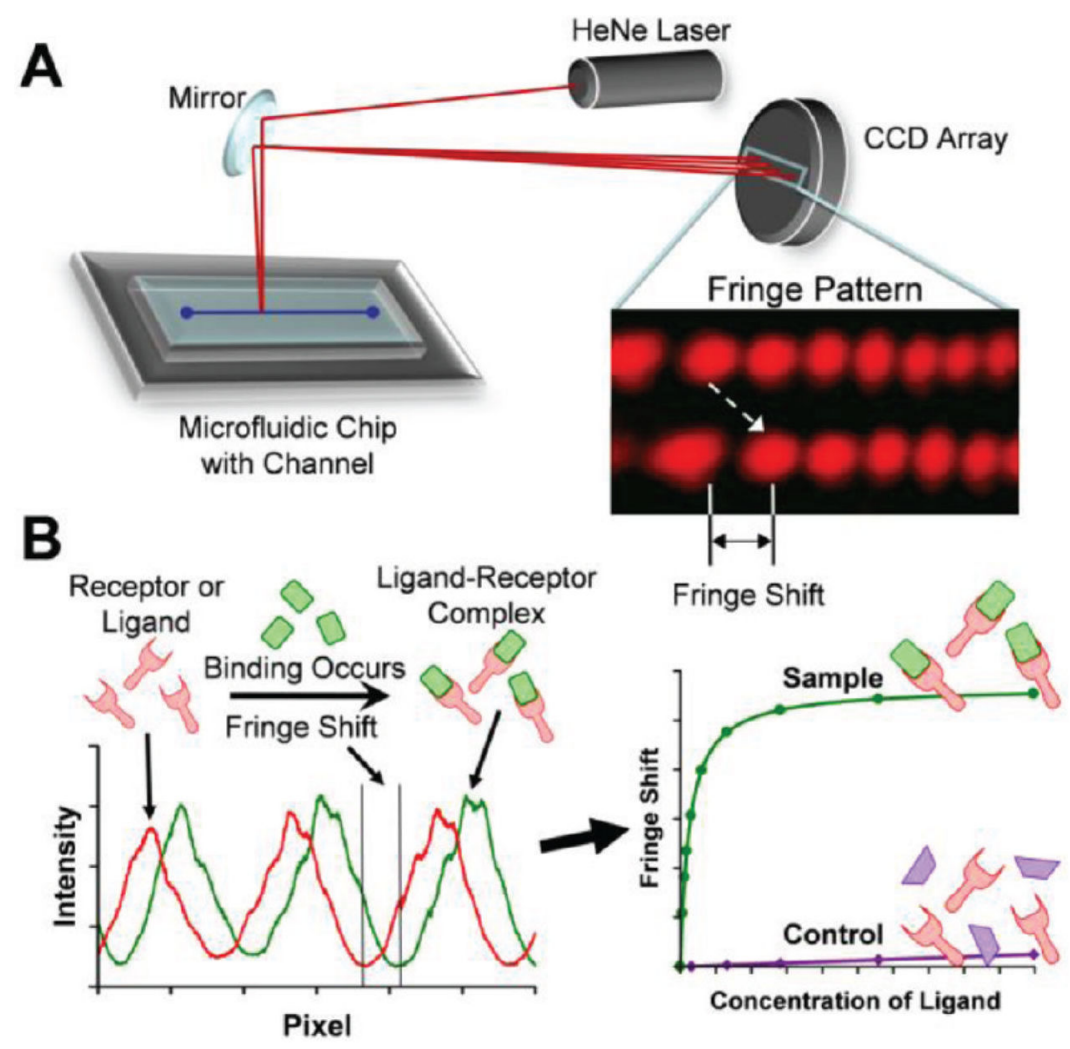

Figure 6.

(A) Block diagram of backscattering interferometry (BSI). (B) Cartoon illustration of the fringe shift seen upon binding and the resulting BSI signal. 

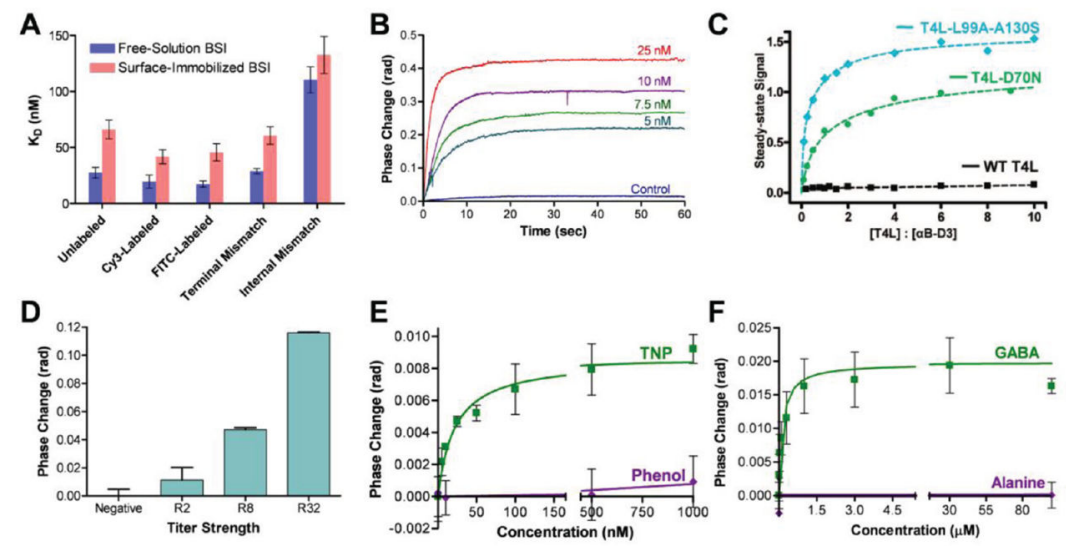

Figure 7.

(A) BSI shows the difference in binding affinities for free-solution and surface-immobilized DNA hybridization. ${ }^{25}$ (B) BSI detects the kinetic interaction of calmodulin and trifluoperazine. From ref 106. Reprinted with permission from American Association for the Advancement of Science, Copyright 2007. (C) Shows that the magnitude of binding as detected by BSI for $a$-crystallin to different T4L lysozyme mutants. Reprinted from ref 109. Copyright 2009 American Chemical Society. (D) Quantitative measurement of titer strength for syphilis in human sera samples. Ref 108-Reproduced by permission of The Royal Society of Chemistry, Copyright 2010. (E) Binding of trinitrophenol to its antibody using an end point assay. Reprinted with permission from ref 107. Copyright 2011 John Wiley \& Sons, Inc. (F) Binding of GABA to its receptor in a native cell membrane. Reprinted with permission from ref 105. Copyright 2011 Nature Publishing Group. 